\title{
UN CONDISCÍPULO ESPAÑOL DE ALEXANDER VON HUMBOLDT EN LA BERGAKADEMIE DE FREIBERG: JOSEF RICARTE Y SU INFORME SOBRE EL MÉTODO DE AMALGAMACIÓN DE BORN (1788)*
}

\author{
Francisco Pelayo \\ Instituto de Historia de la Ciencia y Documentación López Piñero (CSIC-Universidad de Valencia) \\ Sandra Rebok \\ Dpto. de Historia de la Ciencia, IH, CH, CSIC
}

\section{RESUMEN}

Se estudia la labor de Joseph Ricarte, pensionado en París y luego en Centroeuropa, para estudiar el método de amalgamación de Born. El trabajo de Ricarte fue especialmente interesante en la Escuela de minas de Schemnitz, a cargo del profesor Antón Ruprecht, en 1787, aunque también se exponen los viajes de aprendizaje con Andrés Manuel del Río por diversas regiones centroeuropeas (Alta y baja Hungría, Austria, Bohemia,etc...) hasta su llegada a Freiberg, en Sajonia, donde estudiaron con A. Werner y fueron compañeros de Alexander von Humboldt. Acompaña al artículo una disertación de Ricarte sobre las mejoras introducidas por Ruprecht al método del barón de Born.

PALABRAS CLAVE: Joseph Ricarte, Alexander von Humboldt, minería, amalgamación, siglo XVIII.

\section{SUMMARY}

This article presents the work of Joseph Ricarte who stayed in Paris as a fellow and, afterwards, he went to Central Europe to study Born's amalgamation method. The work of Ricarte was specially interesting at the School of Minery in Schemnitz directed by profesor Antón Ruprecht at that time (1787). The article also refers to the instruction journeys made by Josep Ricarte and Andrés Manuel del Río to different regions of Central Europe (Hungary, Austria, Bohemia, etc...) until their arriving in Freiberg, Saxony; where they studied with A. Werner and both of them were col-

* Trabajo realizado en el marco del Proyecto BHA2000-1230 Plan Nacional I+D+I (2000-2003) y en el de la Beca I3P del CSIC (MCYT). 
leagues of Alexander von Humboldt. The article is supported by a dissertation of Ricarte about

Ruprecht improvement of Born's method.

KEY WORDS: Joseph Ricarte, Alexander von Humboldt, mining, amalgamation, $18^{\text {th }}$ century.

\section{INTRODUCCIÓN}

Uno de los aspectos en que incidieron los gobiernos ilustrados españoles en su intento de reformar y modernizar las industrias militar y mineras, fue la dotación de pensiones para la ampliación de estudios en centros científicos y tecnológicos europeos. El objetivo principal de este plan era que los pensionados adquiriesen una sólida formación científico-técnica, asimilando las teorías y prácticas científicas más innovadoras. Así, a su vuelta a España, estarían capacitados para ejercer una labor docente y para organizar la puesta en marcha de nuevos procedimientos que permitiesen rentabilizar la explotación de los recursos. Los pensionados, conforme a sus instrucciones, en algunos casos reservadas, tenían que recoger información sobre las prácticas tecnológicas, especialmente de las consideradas secretas y prohibidas a los extranjeros, dibujar planos y hacer modelos de las máquinas empleadas en los trabajos de minas, documentarse sobre la organización de las operaciones y la administración de la producción, etc.

Los ministerios de Guerra, Marina, Indias y Hacienda se implicaron en la financiación de pensionados a los principales centros mineros centroeuropeos. Fueron fundamentalmente las academias mineras y las fundiciones de Freiberg (Sajonia) y de Schemnitz (actual Eslovaquia), ésta última perteneciente entonces al imperio de los Habsburgo, los centros elegidos a los que asistieron los pensionados para instruirse en las modernas técnicas metalúrgicas e informar acerca de la maquinaria y de las operaciones más innovadoras empleadas en estas instituciones adelantadas en la teoría y prácticas mineras.

El establecimiento de la enseñanza en la Bergakademie de Freiberg (Sajonia) y los primeros pensionados españoles.

Durante el reinado de Fernando VI, en los años centrales del siglo XVIII, el marqués de la Ensenada, ministro de Marina, Guerra e Indias, fue el primero en organizar misiones y viajes de espionaje industrial a Europa con el objeto de que los comisionados elegidos tomaran notas de la tecnología empleada, entre otros campos, en la industria minera. Así, tras el antecedente de los in- 
formes enviados por Antonio de Ulloa sobre las minas alemanas y húngaras ${ }^{1}$, los primeros pensionados que cursaron estudios de minería y metalurgia en Freiberg, unos años antes de que se fundara en 1765 la famosa Bergakademie, fueron José Manes y Francisco Estachería ${ }^{2}$.

Fue durante la estancia de estos dos comisionados en Turín en 1752, cuando se informaron del buen nivel de estudios teóricos que existía en Freiberg y de su aplicación al rendimiento y explotación de las minas. Al no contemplarse en las instrucciones de su viaje su paso por esta localidad minera, consiguieron tras solicitarlo permiso para desplazarse a Freiberg. Allí permanecieron dos años, entre agosto de 1753 y el mismo mes de 1755, completando su formación tecnológica. En sus cartas a España no pudieron enviar informes muy detallados, ya que la correspondencia de los extranjeros era abierta por las autoridades sajonas. A pesar de la reserva con que se rodeaban las prácticas tecnológicas, Manes y Estachería pudieron informar sobre procesos considerados como secretos de Estado en Sajonia, como eran los de la obtención y aplicación del cobalto y la fabricación de la porcelana ${ }^{3}$.

Sería pocos años después del paso por Freiberg de Manes y Estachería, cuando en 1765 desde la comisaría general de minas de Sajonia se impulsó la creación de un sistema de enseñanza en la Bergakademie. Los objetivos que se plantearon fueron la formación de funcionarios mineros cualificados, la investigación sobre los recursos mineros y minerales, la promoción de innovaciones tecnológicas $\mathrm{y}$, en general, la rentabilización económica de las explotaciones mineras. Entre los profesores encargados de la docencia se encontraba A. G. Werner (1749-1817), cuyas ideas en los campos de la geología y mineralogía tuvieron una enorme aceptación en Europa. A su vez, alumnos de Werner fueron Alexander von Humboldt (1769-1859) y el poeta Friedrich von Hardenberg (1772-1801), más conocido como Novalis, quien en dos de sus obras homenajeó las enseñanzas recibidas de su maestro Werner ${ }^{4}$.

1 LAfuente, A. Peset, J. L. (1981), «Política científica y espionaje industrial en los viajes de Jorje Juan y Antonio de Ulloa (1748-1751)», Melanges de la Casa de Velázquez, 17, 233-262.

2 Helguera QuiJada, J. (1988), «Las misiones de espionaje industrial en la época del Marqués de Ensenada y su contribución al conocimiento de las nuevas técnicas metalúrgicas y artilleras a mediados del siglo XVIII». En: Mariano Esteban Piñeiro et al. (Coords.), Estudios sobre la Historia de la Ciencia y de la Técnica, Valladolid, Junta de Castilla y León, vol. II, 671-695.

3 Ibidem, p. 690.

4 Sobre la influencia werneriana en España puede verse el apartado «Las ideas de Werner en España» en: Lafuente, A.; Puig-SamPer, M.A.; Hidalgo, E.; Peset, J.L.; Pelayo, F. 
A comienzos de los años setenta, Ramón $M^{\mathrm{a}}$ Munibe (1751-1774), hijo del conde de Peñaflorida, fue enviado por su padre, acompañado de su preceptor el abate Cluvier, en un viaje de estudios por varios países europeos ${ }^{5}$. Tras pasar por París, el condado de Foix, Holanda y Suecia, Munibe llegó a Freiberg en el verano de 1772. El plan de estudios que tenía previsto llevar a cabo en la escuela minera de esta localidad consistía en instruirse en los principios de la Geometría subterránea y el uso de los mapas de las minas; realizar un curso sobre la teoría de los filones y el modo de trabajarlos; adiestrarse en los principios de la mecánica de las minas, especialmente en lo relativo a las diversas máquinas que se empleaban en ellas y, por último, formarse y capacitarse en la teoría y práctica de la fundición ${ }^{6}$.

Todo fueron facilidades para que Munibe pudiera aprender los fundamentos básicos de los trabajos de minas empleados en Freiberg, ya que el Elector de Sajonia expidió un documento para que intendentes, capitanes, directores y maestros le mostrasen y enseñasen todo lo que quisiese, a excepción de las minas y prácticas que eran consideradas secretas. En todos sus recorridos fueron acompañados del Profesor del Instituto, del Maestro de Minas, de un secretario, de un director de fundición y de dos oficiales subalternos. A todos ellos debieron sufragarles la comida mientras duró la visita. Además, correspondieron las múltiples atenciones recibidas invitando a Gellert, Director General de Fundiciones, al profesor de la clase teórica de venas y filones y a los oficiales mayores de Artillería e Ingenieros. En Freiberg les comentaron la estancia años antes de Manes y Estachería ${ }^{7}$. Posteriormente Munibe se dirigió a Viena, recorriendo los centros mineros austríacos.

Los informes que poseían las autoridades españolas tras el paso por Freiberg de Manes, Estachería y luego de Munibe debieron ser inmejorables. Estas excelentes referencias fueron determinantes para que en las últimas décadas del siglo XVIII se enviaron varias tandas de pensionados en fin de que se adiestrasen en la academia minera sajona en los principios teóricos y prácticos de las operaciones metalúrgicas y en la organización de las explotaciones

y SELLÉs, M. (1996), «Literatura científica moderna». En: F. Aguilar Piñal (Ed.), Historia Literaria de España en el siglo XVIII, Ed. Trotta/CSIC, pp. 995-1000.

5 Cf. URQuiJo, J. de (1929), «Los amigos del País (según cartas y otros documentos inéditos del XVIII), San Sebastián, Imprenta de la Diputación de Guipúzcoa, págs. 43-90 y Arocena, F. (1965), «[Cartas de Don Ramón Ma de Munibe a su padre Don Xavier y a la Real Sociedad Bascongada de los amigos del País]», Colección de documentos inéditos para la historia de Guipúzcoa, nº 6, San Sebastián, 1965, 39-76.

6 AROCENA (1965), p. 68.

7 Ibidem, p. 70. 
mineras. Pero además, como el propio Munibe apuntó, era conveniente instruirse en los aspectos mecánicos y en el conocimiento de las máquinas utilizadas en los trabajos de las minas; y en este campo, los establecimientos, fábricas y fundiciones del imperio austriaco tenían un nivel superior al de los centros mineros germánicos.

En los inicios de los años ochenta fueron pensionados a Sajonia y Centroeuropa Francisco Angulo ${ }^{8}$, Eugenio Izquierdo y los hermanos Juan José y Fausto de Elhuyar'. Estos notables ilustrados contribuyeron al desarrollo del conocimiento científico, desempeñando puestos destacados en la organización de la política científica y tecnológica española de la época. El itinerario que siguieron estos comisionados en su viaje de formación por los centros docentes y establecimientos mineros sajones y centroeuropeos sirvió de modelo para el que desarrollaron años después los miembros de la siguiente generación de pensionados, algunos de los cuales coincidieron en Freiberg con Humboldt ${ }^{10}$.

\section{El adiestramiento de Josef Ricarte, condiscípulo de Humboldt en Freiberg}

A comienzos de 1786, el ministro de Indias José de Gálvez, tras llegar a España tiene noticias de que el barón Ignaz von Born (1742-1791) había diseñado un nuevo proceso de beneficio de minerales argentíferos, comisionó a Fausto de Elhuyar (1757-1833), junto con tres jóvenes que se encontraban pensionados en París, Fernando Casado de Torres, Joseph Ricarte y Andrés Manuel del Río (1764-1849) - posteriormente Elhuyar propuso como pensionado a Francisco Codón_- ${ }^{11}$, para que se adiestraran en Centroeuropa en el

8 LÓPEZ DE AzConA, J.M. (1987), «Mineros destacados del siglo XVIII: Francisco de Angulo (17...-1815). Primera Dirección General de Minas (1788-1815)», Boletín geológico y Minero, t. XCVIII-VI, 864-875.

9 Galvez CaÑERo y Alzola, A. (1933), «Apuntes biográficos de Fausto de Elhuyar y de Zubice», Boletín del Instituto Geológico y Minero de España, LIII, 8, 379-629.

10 Puig Y LARraZ, C. (1894), «Viajes por Bohemia, Moravia, Austria, Hungría, Estiria, Salzburgo y Auvernia en los años 1780 y 1781. Itinerarios escritos por D. Francisco Angulo», Boletín de la Sociedad Geográfica de Madrid, XXXVI, 177-192, 210-266 y 327-351 y PELAYO, F. (1990), «La adquisición de las técnicas mineras en la España de la Ilustración». En: J. Fernández Pérez e I. González Tascón (Eds.), Ciencia, Técnica y Estado en la España de la Ilustración, Zaragoza, M.E.C.

11 Sobre los pensionados españoles en París en el siglo XVIII puede consultarse PELAYO, F y GARILLETI, R. (1992), «La formación y actividades botánicas de A.J. Cavanilles», Ascle- 
nuevo método de amalgamación de Born y a su vuelta lo aplicaran en las minas americanas ${ }^{12}$.

Mientras Fausto de Elhuyar ejecutaba su encargo y evaluaba las ventajas del método de Born, los pensionados que habían llegado desde París, Josef Ricarte y Andrés Manuel del Río, ya que Codón continuó en la capital francesa, comenzaron en Schemnitz con Antón Ruprecht (1748-1814) ${ }^{13}$, profesor en la academia de minería, su formación en química, mineralogía, metalurgia y en las prácticas mineras que más adelante deberían aplicar en América.

En enero de 1787 iniciaron Ricarte y del Río su asistencia a los cursos de técnicas mineras y de química. En el primero de ellos, según el informe que envió Ricarte, les enseñaron, entre otras prácticas:

«1 $1^{\circ}$, la formación de las montañas, su estructura o cobertura interior, las vetas y venas que en ellas se encuentran, las sustancias de que se componen y los metales que cada género de ellas suelen encerrar dentro de sí. $2^{\circ}$, el arte de descubrir minas, así en montes donde ya se benefician otras, como los que hasta aquí no se ha hallado ni buscado ninguna, añadiéndose a esto la prudencia y circunspección de que debe usarse para determinar si conviene poner un asiento de minas en el lugar donde se descubriese alguna, por ser punto de mucha importancia para los interesados. $3^{\circ}$, el modo como los mineros deben de cortar la piedra para desmoronarla con facilidad, el de señalar el sueldo a las varias clases de ellos, si trabajasen a jornales, y si a destajo lo que se le hubiere de dar por cada cubo que desmontaren, conocida su calidad y dureza. $4^{\circ}$, el modo de hacer taladros horizontales o como dicen Galerías, los cuales, según hayan de servir para sondear o examinar alguna parte del monte, para la circulación del aire en la mina, para dar subida a las aguas que se filtran, o bien para la saca de los minerales, han de ser diferentes; y como a veces una sola de estas galerías puede servir para todos estos efectos, no se han olvidados los casos y circunstancias en que sean posible juntar tantas ventajas. $5^{\circ}$, el modo de hacer las perpendiculares, o como dicen, pozos, también diferentes a lo menos en cuanto su grandor, según el porque con ellos se propone, porque si hubiesen de servir para entrar y salir de la mina, para sacar por medio de máquinas adecuadas los minerales, piedras y aguas, para introducir las maderas que se necesitan, así para fortificar la mina, como para la construcción y compostura de las máquinas que obran dentro de ella...» ${ }^{14}$.

pio, XLIV, 129-154 y García Belmar, A. y Bertoméu SÁnchez, J.R. (2001), «Viajes a Francia para el estudio de la Química, 1770-1833», Asclepio, LIII, 95-139.

12 Véase Pelayo, F. y Rebok, S. (2002-2003), «Fausto de Elhuyar y la Societät der Bergbaukunde. Un proyecto científico de red europea para la difusión de las prácticas minerometalúrgicas», Cronos, vol. 5-6, 67-90.

13 Para la biografía de Ruprecht consúltese: PRÓDER, I. (1992), «Einige biographische Daten über Anton Ruprecht (1748-1814)», Technikatörténeti Szemle, 19, 194-197.

14 Archivo General de Indias (AGI), Indiferente general, Legajo 1798, Expediente de los mineros sajones que pasaron a Indias. Incidencias 1786 a 1793», fols. 540r-541v. 
Si en cuanto a técnicas mineras la formación era intensiva, en química, según comentaba Ricarte, no habían adelantado tanto, ya que sólo les habían impartido unos conocimientos preliminares de esta ciencia: su objeto, su historia, los instrumentos utilizados para las operaciones químicas, tanto los antiguos como los modernos, los hornos y lo que había de entenderse por ácido, álcali, sales, tierras, metales, etc. Finalmente les habían explicado las leyes de las afinidades químicas, las leyes físicas y la repulsión y atracción entre los cuerpos. Por las tardes, en el laboratorio se repetían los experimentos que habían sido expuestos en el curso teórico matutino.

Tras el período de aprendizaje en la academia minera de Schemnitz, Ricarte y del Río recibieron unas instrucciones en 1790 cuya finalidad era que completaran su adiestramiento, visitando los más importantes centros mineros europeos para que tomaran nota de las técnicas mineras más avanzadas. Se dispuso con este objetivo que en un primer recorrido pasasen a reconocer los asientos mineros más notables de la baja Hungría (Eslovaquia) que no hubiesen aún visitado, para a continuación dirigirse hacia el este, a los correspondientes a la región de la alta Hungría (Rosenau, Schmöllnitz, Göllnitz), aprovechando para visitar las salinas de Transilvania que se encontraban en la frontera de dicha zona. Durante este viaje, para completar su formación, los pensionados debían aprender los diferentes tipos de manipulaciones e instruirse en todas las operaciones, y así después saber cual convenía aplicar en cada caso. Tenían que adquirir también el conocimiento suficiente en todo lo concerniente a la historia natural del reino mineral, con el objeto de diferenciar y poder describir las diversas clases de montañas. Tras dos o tres meses debían regresar a Viena, para desde allí emprender un nuevo recorrido. En este viaje visitarían las fundiciones y fábricas de hierro y acero de Estiria y Carintia. Después deberían pasar a Idria, para observar los trabajos subterráneos y los de beneficio de los minerales de azogue. Seguirían hacia Bleiberg (Carintia), zona rica en minas de plomo cuyos minerales se fundían en hornos de reverbero, y entrarían a continuación en el Tirol, fijándose especialmente en las operaciones de beneficios utilizadas en las minas de cobre. Su viaje continuaría en dirección a Salzburgo, a fin de visitar minas y salinas, antes de volver a Viena, por lo que necesitarían al menos cuatro meses para completar este segundo recorrido. En el tercero deberían recorrer Bohemia, pasando por varias minas, como las de Gutewasser antes de llegar a Praga. Desde esta ciudad se dirigirían a visitar minas de estaño, para dirigirse después hacia Joachimsthal y, siguiendo las fronteras de Sajonia, entrarían en este territorio, con destino a Dresde, donde pedirían las licencias necesarias para pasar a Freiberg. Dos meses era el tiempo que se estimaba para completar este reco- 
rrido. En Freiberg deberían seguir un curso de mineralogía con A. Werner, e instruirse en labores subterráneas y arreglos de las máquinas de aquellas minas. Continuarían hacia Turingia, también en Sajonia, donde examinarían minas de cobre y salinas, para desde allí dirigirse hacia el Harz (Hannover), donde en dos meses deberían visitar Clausthal, Zellerfeld, y otras localidades mineras. Desde Hannover pasarían al palatinado del Rhin con objeto de inspeccionar las minas de azogue, en cuyo procedimiento de beneficio se debían instruir perfectamente. Proseguirían hacia Lieja, donde reconocerían las minas de carbón, viajando después hacia España, vía Inglaterra, en donde se informarían acerca de los trabajos de las minas de carbón y sobre las fundiciones de hierro. Como para llevar a efecto estos viajes no bastaba con su pensión anual de 12.000 reales, se les ayudaba con otros 8.000 para cubrir gastos ${ }^{15}$.

A través de las memorias e informes enviados por Ricarte y del Río al ministerio se tiene conocimiento de que, no sólo cumplieron con el plan de viaje previsto sino que además completaron su formación teórica, que a su vez era acompañada de experiencias prácticas en laboratorios.

Otro grupo de pensionados para el aprendizaje de las técnicas minerometalúrgicas, en este caso financiado por el ministerio de Hacienda español, llegó a Viena en abril de 1788. Estaba formado por Manuel Angulo, José Miaja, Juan López Peñalver y Enrique Schnellenbühel, éste último un ingeniero militar alemán que había entrado al servicio de la corona española a través del conde de Aranda. En la capital austriaca coincidieron con Ricarte y del Río, quienes les buscaron alojamiento y les presentaron a Ruprecht.

A través de la correspondencia de Manuel Angulo con su hermano Francisco, Director General de Minas del Reino, se puede obtener alguna información tanto de la personalidad de Ricarte como de los problemas prácticos y las propuestas para resolverlos, que se generaron en los establecimientos mineros centroeuropeos, en relación al método de amalgamación que había diseñado Born ${ }^{16}$.

15 AHN, Estado, Leg. 4671: «Instrucciones que de orden del Rey se forman para que sirvan de gobierno a los tres pensionados dn. Josef Ricarte, dn. Andrés Manue del Río y dn. Francisco Codón en los estudios y viajes que deben emprender a fin de completar sus conocimientos y regresar a España para ser empleados con proporción a su instrucción y adelantamientos». San Lorenzo, 26 Septiembre 1790.

16 Puig y Larraz, G. (1898), «Viajes de estudio por Europa (Francia, Austria, Alemania Central, Prusia, Holanda, Suecia, Noruega e Inglaterra) durante los años 1788 á 1795. Cartas científico-familiares de D. Manuel de Angulo y Correa recogidas, coleccionadas y anotadas por...», Boletín de la Sociedad Geográfica de Madrid, T. XL, 1898 ,pp 145-192. y 260-295; T. XLI, 1899, pp. 23-55, 193-223 y 283-301; T- XLII, 1900, pp. 37-56, 60-82 y 127-162. 
En las cartas de Manuel Angulo, Ricarte es descrito como un personaje muy conflictivo, enfrentado tanto a su compañero del Río como al propio Fausto de Elhuyar. Y si bien en un principio se comportó de manera amable, ayudando en sus estudios a Angulo, éste, tras la enseñanza común que siguieron en Freiberg, terminó por no querer saber nada de él. Le consideraba perverso, hipócrita e intrigante, y le achacaba que con su actitud hacia él y sus compañeros Miaja y Schnellenbühel, había conseguido perturbar el desarrollo normal del curso impartido por Werner ${ }^{17}$. Casi con certeza tuvo que ser el mismo al que asistió Humboldt, ya que por las fechas de estancia en Freiberg de los cuatro pensionados de España, se sabe que coincidieron con el naturalista alemán en las clases que Werner explicaba en la Bergakademie.

Humboldt había mostrado su interés por cuestiones geológicas en una obra sobre las rocas basálticas de Unkel, elaborada siguiendo los criterios descriptivos y las ideas neptunistas de Werner, que había sido el resultado de un viaje que efectuó por la región en otoño de $1789^{18}$. Envió un ejemplar de este trabajo a Werner, junto con una carta en la que elogiaba su labor en el campo de la sistemática mineralógica, comentándole que confiaba poder asistir en un futuro próximo a sus cursos de Freiberg ${ }^{19}$. Humboldt cumplió su deseo al año siguiente y así asistió, como alumno externo, a los cursos de la Bergakademie desde junio de 1791 hasta febrero de $1792^{20}$.

Tras concluir con su aprendizaje en Freiberg, Ricarte continuó con su viaje de instrucción previsto desde el ministerio de Indias, siendo nombrado al finalizar su período de adiestramiento en las prácticas mineras y metalúrgicas, director de las Minas de Quito. Sin embargo, a comienzos de 1794, murió cuando iba a embarcarse en La Coruña para dirigirse a su destino en las colonias americanas ${ }^{21}$.

17 Ibidem, T. XLII, 1900, pp. 39-49 (Carta escrita desde Freiberg el 21 de Abril de 1792 por Manuel Angulo a su hermano Francisco).

18 Humboldt, A. von (1790), Mineralogische Beobachtungen über einige Basalte am Rhein, Braunschweig, Schulbuchhandlung (reedición en 1991).

19 La carta de Humboldt a Werner fue publicada en KÜHN, P.; WOLFHART, L. \& Schmidt, P., «Marginalien zu Humboldts Schrift Mineralogische Beobachtungen über einige Basalte am Rhein», pp. 129-131 de la reedición de la obra anterior publicada en 1991. Asimismo se encuentra en: JAHN, I. \& LANGE, F. (Eds.) (1973), Die Jugendbriefe Alexander von Humboldts 17871799, Berlín, pp. 99-100.

20 Puede verse: SEnNEwALD, R. (1994), «Die Studenten an der Bergakademie Freiberg 1791/92 und Alexander von Humboldt Freundeskreis in Freiberg», Humboldt-Tage in Bad Steben, t. 2, Bad Steben, pp. 147-174.

21 CAYCEDO, B.J. (1971), D'Elhuyar y el siglo XVIII neogranadino, Ed. Kelly, Bogota, pp. 223-224. 


\section{Las mejoras propuestas por Ruprecht al método de amalgamación}

Por lo que respecta a la rentabilidad del método de amalgamación europeo, cuya comprobación era una de los motivos por los que había sido enviado Ricarte como pensionado a Centroeuropa y Sajonia, parece por la correspondencia de Angulo a su hermano, que surgieron muchas dudas en los establecimientos mineros europeos, en relación a la eficacia del procedimiento propuesto por Born.

Angulo comentó en su correspondencia que la impresión que fue surgiendo en los establecimientos mineros de Hungría y Bohemia tendía a cuestionar la utilidad y la eficacia del nuevo método de beneficio de minerales. El propio Ruprecht, decía, consideraba que las máquinas y el método de amalgamación utilizados en Bohemia eran muy defectuosos, y que eran más ventajosos los que él usaba en Schemnitz. En ocasiones, el problema radicaba en la falta de condiciones necesarias para efectuar los ensayos, llegando el caso de tener que suspenderse las pruebas del nuevo procedimiento por la falta de agua para poner en funcionamiento las máquinas. Además, para complicar más el asunto, había intereses e intrigas promovidas por los partidarios de volver al procedimiento de fundición. Todo esto provocaba, a juicio de Angulo, que las operaciones y sus resultados se rodearan de secretos y que nadie dijera la verdad sobre la eficacia real de la amalgamación ${ }^{22}$.

No sólo Born y Elhuyar, como es conocido ${ }^{23}$, realizaron esfuerzos por mejorar el método de amalgamación. Ruprecht también propuso una serie de sugerencias con las que pretendía perfeccionar el procedimiento para beneficiar minerales de oro y plata. Con esta finalidad sugirió la conveniencia de triturar en granos muy finos el mineral antes de aplicar el proceso de quemado, así como alternar la adición de sal en las tostaciones. En su opinión, la transformación de la harina mineral en una pasta se prestaba más fácilmente a la amalgamación.

Otra propuesta de Ruprecht se dirigió a mejorar las instalaciones donde se realizaba el proceso, de manera que para facilitar la extracción del metal contenido en las mezclas, en lugar de emplear los barriles de Born, recurrió a una especie de cajón redondo, hecho de planchas y recubierto de cobre en su mitad inferior. Elhuyar describió así la propuesta de Ruprecht:

22 Puig y LarraZ, G. (1898), Op. Cit., T. XLI, 1899, pp. 30-31 y p. 193.

23 Un estudio que trascribe y comenta las experiencias de Elhuyar sobre la amalgamación puede verse en: GUZMÁN, J. (1941), «Las disertaciones metalúrgicas de Elhuyar», Boletín del Instituto Geológico y Minero de España, t. LV, $3^{\mathrm{a}}$ serie, pp. 437-572. Información histórica se encuentra en PELAYO y REBOK (2002-2003). 
«El [cajón] que empleó [Ruprecht] en los primeros ensayos tenía 38 pulgadas de largo y dos pies de diámetro. Su sección transversal era exactamente circular. Este cajón llevaba en su centro y longitudinalmente el árbol horizontal de una rueda que se hacía girar durante la operación. Este árbol estaba provisto de dos filas de cucharas o especie de aletas recurvadas distribuidas en doble espiral en toda su longitud y distantes entre sí una pulgada, que servían para remover las mezclas. Se pone en este cajón el mercurio con los minerales en el mismo estado que en las calderas, con excepción que no se añade más que el agua necesaria para reducir todo a un barro espeso. Es fácil ver que a cada vuelta del árbol las cucharas deben revolver la mezcla y hacerla cambiar de lugar, deben también dividir el mercurio y mezclarle íntimamente con las otras materias, tanto más cuanto su consistencia favorece esta división. Esta misma consistencia, así como la velocidad del movimiento, el cual se puede modificar a voluntad, facilitan por igual la unión del mercurio con la plata y el oro a medida que estos metales se encuentran. Estas circunstancias no pueden menos de producir una extracción completa y más perfecta del oro y la plata de sus minerales que el método de las calderas; en los ensayos que se han hecho, la plata se había combinado enteramente con el mercurio al cabo de seis u ocho horas, y el oro, al cabo de veinte horas, mucho más completamente que en las calderas. Resultados tan ventajosos impulsaron a establecer este método, y Mr. De Ruprecht ha comenzado, en efecto, a construir cajones de 24 pies de largo y ocho pies de diámetro para disolver de una vez 60, 80 y hasta 100 quintales de mineral» ${ }^{24}$.

Basándose en las pruebas efectuadas por Ruprecht, Ricarte envió un informe manuscrito, cuyo original pasó a manos de Francisco Angulo, como Director General de Minas, y que en la actualidad se conserva en el Instituto Geológico y Minero de España (IGME) ${ }^{25}$. Este informe, trascrito a partir de la copia que se conserva en la Biblioteca de Palacio ${ }^{26}$, es el que se presenta a continuación.

En la fecha de redacción de la disertación de Ricarte, 1788, el método de amalgamación europeo abría una expectativa interesante, ya que se conside-

24 GuZMÁn, J. (1941), Op. cit., pp. 106-107.

25 Biblioteca IGME, subserie «Apuntes de Angulo», Leg. 5, carp. 2, «Descripciones por Josef Ricarte escritas en 1787 y 1788 acerca de los métodos de amalgamación en Hungría», 15 folios.

26 Agradecemos a la Real Biblioteca (Palacio Real) el permiso para reproducir el manuscrito de la R.B. II/2853, fols. 250r-276 v: «Disertación de D. Joséf Ricarte sobre el método de amalgama que se usa en los asientos de Neusohl y de Glashütte en Alemania, para sacar por azogue, y en cubas la ley a los minerales de oro y de plata...», cuya referencia se encuentra en el Catálogo de la Real Biblioteca, tomo XI, Manuscritos, vol. III, Madrid, Patrimonio Nacional, p. 321. Se ha conservado la ortografía original. 
raba que constituía una innovación tecnológica que podría introducirse con éxito en las minas americanas de España. En ese momento era difícil de prever el fracaso posterior de la expedición minera dirigida por Nordenflicht y las experiencias frustradas de Elhuyar y Sonneschmidt en Nueva España, en sus intentos de aplicar el método de amalgamación de Born en los dominios coloniales españoles de América. 


\section{Disertacion de D. Josef de Ricarte}

sobre

el método del Amalgama, que se usa en los asientos

de Neusohl, y de Glashutle en Alemania,

para sacar por azogue, y en cubas la ley

á los Minerales de Oro, y Plata.

Inventado por el Baron de Born, y perfeccionado

á costa de muchas investigaciones, y pruebas

Por

el docto Profesor Mr. de Ruprecht:

Por medio del qual,

segun un experimento que se hizo en el año de 1787, y á que asistió el mismo Ricarte, se advierte, que amalgamando, y quemando dos veces Minerales con quatro onzas de plata, que contengan dos adarmes y medio de oro por marco, unicamente se pierden tres por ciento del primero, y quince por ciento del segundo, con muy moderado consumo de azogue; á cuya ventaja se añade la del ahorro de calderos, molinetes, y demas instrumentos indispensables en toda otra maquina.

Explica

el modo de hacer la manipulacion, y presenta Diseños de las Cubas, y demas instrumentos; con varias advertencias utiles á los Beneficiadores, tanto para las labores de minerales con sola plata, como con esta, y oro.

Modo de sacar por azogue, y en cubas la ley á los minerales de Oro y Plata

Pocos, ó ningun descubrimiento sale tan acabado de las manos de su Artifice, que de alli á algun tiempo no se retoque, perfeccione y cambie á veces de modo que su mismo Inventor lo desconociera viendole. Confirmalo asi lo que se ha practicado, y practica aun al presente en los Asientos de Neusohl, y de Glashutle á cerca del metodo de amalgama inventado y publicado $\mathrm{p}^{\mathrm{r}}$. el Baron de Born por Mayo del año de 1786, desde cuio tiempo lo há perfeccionado de modo el Profesor de Ruprecht, y hecho tantos y tales cambiamientos, que ponen en duda á qual de ambos hayan de atribuirse y deberse las utilidades que en adelante por su medio se consigan. Salio aquel con su obra sobre esta labor en la qual ensoña y defiende ser mui util por un solo experimento que se hizo en el ultimo de los citados asientos con mil quintales de mineral, que contenian á la verdad quatro onzas de plata cada uno, pero mui poco oro, y del qual no lleva cuenta en la que hace pag. 185 para probar sus ventajas sobre la fundicion cuio fin era el de dicho experimento, ó prueva. Despues de hecha esta con mucho estudio y cuidado se entregaron á la misma Fabrica minerales mas ricos en dicho metal, los quales amalgamó; pero contra lo que se esperaba, pues jamas se obtuvo por medio del metodo publicado en la citada obra sino $1^{\mathrm{a}} / 5$ y quando mas $1 \%$ parte del que realmente contenian y llevaban, y asi quedaron los desechos como era 
natural mui ricos en el, de suerte que según un ensaye general que de ellos se hizo por Agosto del año 1787, al qual asisti describiendole, y embiandole al oficial mayor de la Embaxada de Viena para que lo entregara á $\mathrm{D}^{\mathrm{n}}$ Fausto de Elhuiar, y sirviera para su gobierno, quedaron en cada quintal nueve dineros de plata (4 $1 / 2$ adarmes) llevando esta 32 de oro por marco, según lo qual y la cuenta que alli hice, quedó en 19000 quintales de residuo que se havian amalgamado hasta alli valor de 400 mil reales los que cargandose como deben á los gastos que esta labor ocasiona, sale sin duda cada marco de plata la mitad mas caro que por la fundicion y mas del doble de lo que se lee en el citado lugar de la obra de Born. Andando el tiempo se reparó asi mismo que los gastos no de construccion de la Fabrica, pues de estos no se menta nada en aquella obra, aun que pudieran, pues son extraordinarios, sino de remiendos y composturas de una infinidad de Maquinas, ingenios, y vasos que la componen suben mucho mas de lo que se pensó, pues por todos no se ponen sino $8 \mathrm{Kr}$ por quintal de mineral en lugar que solo los de calderos y molinetes, los exceden, en el el corto espacio de 16, ó diez y ocho dias que estuve en Neusohl por septiembre del año pasado se agugerearon, y hecharon á perder 31 de 80 que havia por atacarlos, y corroderlos continuamente las caparrosas y sales que se forman en los ornos, y andan con el mineral. La maior parte se lleva tambien el azogue que se amalgama continuamente con ellos. Finalmente se ha observado que para sacar 1000 marcos de plata que se han beneficiado hasta aquí en Glasutle y en Neusohl se han consumido pasados 60 quintales de azogue que hacen tres veces mas del que Born trahe, pues se lee pag. 184 que para sacar 482 marcos que se obtuvieron por la mencionada prueba de comparacion, sobre que se funda toda su obra se consumieron solo 50 libras 6 onzas (Adviertase que en esta cuenta no se puso el que se pierde al desazogar las pellas, y que pasa de media onza por marco por que se pensó que siendo una operacion mui mecanica, podria hacerse sin disminucion de azogue, que corresponde á poco mas de1 $1 / 2$ onza por marco, y segun el que realmente se ha consumido en las labores posteriores sube á mas de 6 onzas. Viendo pues el Profesor de Ruprecht, á quien como el varon mas docto, é instruido del cuerpo de Mina, se encargó de introducir el presente methodo en el Reyno de Ungria, donde estan las mas ricas, é importantes de Europa, estos inconvenientes y en particular el del oro, que solo bastaba para que jamas de introdugera ni probara, hizo varios experimentos, y pruevas, tentando varios modos de amalgamar para vencerlos, y mediante ellas inventó aquella manipulacion y Maquina para revolver el mineral de quien di noticia al Exmo Señor Marques de Llano por Mayo del año pasado, describiendo la $1^{\mathrm{a}}$ y dibujando la $2^{\mathrm{a}}$. Mas reparandose luego que aunque á la verdad se sacaba por su medio, casi todo el oro de los Minerales, se necesitaba sin embargo otro tanto tiempo que hasta alli se havía empleado para una misma cantidad de mineral, y que asi no podria amalgamarse en un Asiento regular, sino la mitad de lo que comunmente se beneficia al año en una fundicion de ocho hornos, y asi mismo siendo mui dificultoso y casi impracticable el arrancar á trozos una pasta tan firme como exigia aquella labor, hasta quarenta veces cada minuto juntamente con una cantidad immoderada de azogue (75 por quintal) para lo 
qual no huviera vastado la fuerza de agua que regularmente puede emplearse en estos asientos, y finalmente observando que con dicha Maquina quedaba toda via la incomodidad de los gastos continuos que huvieran ocasionado las cucharas, ó brazos de ella, y que havian de ser forzosamente de cobre fino, como asi mismo los de las planchas con que se havian de aforrar los caxones que havian de ser de lo mismo, vistas, digo, todas estas dificultades se resolvió en esta Camara de Schemnitz que no obstante las ventajas que la ultima manipulacion llevaba sobre la de los calderos y cocimiento sin embargo no era preferible toda via á la fundicion, y asi fue menester que $\mathrm{M}^{\mathrm{r}}$ de Ruprecht excogitara otra mediante la qual se evitasen sino todos, por lo menos los mas principales inconvenientes. Para alcanzarlo havian de observarse dos cosas la primera la firmeza de la pasta que es indispensable para la saca del oro, y la segunda dar á esta un movimiento que describiese circulos perpendiculares al orizonte, como el mas propio para la mezcla exacta del azogue y demas materiales con el mineral, y asi mismo el que tiene menos dificultad, labrando con este genero de pasta. Ningun vaso mas á proposito para ello parecio á dicho Profesor que las cubas, mas Born havia hecho yá con ellas algunos experimentos, que no habiendole salido á deseo las desecha y reprueba como inútiles, y asi havia que vencer todas las dificultades que se leen de la pág. 168 hasta 172 de su obra. No fue esto parte para que se desanimara, y asi emprendió otra serie de pruebas, cambiando con mucha orden, asi las circunstancias que havian de acompañar á la labor como los materiales de la mezcla y sus proporciones. Tengolas todas en mi poder; pero por ser muchas, pues es obra de una mano de papel, y el trabajo de quatro meses continuos, no pueden incluirse en esta descripcion, y solo diré que por ellas se vino en conocimiento de que era necesario quemar y amalgamar segunda vez los minerales para sacarles el oro, pues con la primera labor no era posible lograr sino la mitad ó un poco mas. Repitiose varios dias la manipulacion y mezcla que $\mathrm{M}^{\mathrm{r}}$ de Ruprecht estimó por la mas util y ventajosa de quantas havia probado, y salio con corta diferencia como primero, dando mucho oro, casi toda la plata, y consumiendo una cantidad moderada de azogue. Hizose luego, sobre ello una representacion á la Camara de Minas de Viena formada de todos los oficiales de aquel Asiento, la qual reconociendo su utilidad y ventajas sobre el metodo de Born dio orden á este govierno de Minas por Febrero del presente año para que el mismo Ruprecht para maior certidumbre de dicha Camara beneficiara en los mismos vasos, y según su metodo 293 quintales de mineral algo rico en oro, que á este efecto se havia embiado á Neusohl de las Minas de Kremnitz. No me parecio ser cosa de tan poca importancia para que no me moviera á ir á este asiento donde havia de executarse la unica prueva que se ha hecho hasta aqui de orden de la citada Camara, teniendo por objeto el oro; y asi mismo con las formalidades que se necesitan para conseguir el credito de los sugetos inteligentes en estas materias. Asi que asisti en ella durante todo el tiempo de su beneficio, y se procedio en la forma que se sigue.

Los Minerales que se emplearon, y que como he dicho se juntaron de varias Minas de Kremnitz contenian plata roja, plata blanca Minera argenti rubra, minera argenti alba, quarzum calx terra aluminis spatium ponderosum sulfur, mucho quarzo, 
poca cal, y menos arcilla, tierra pesada y azufre en cantidad moderada. Desmenuzaronse primero con pisones y cernieron con cedazos algo groseros y por donde pudieran pasar granos enteros de mostaza, lo qual se hizo con el fin de que quando se molieran con ruedas de Molino no se quebraran estas, pues sucede frecuentemente, tropezando con algun grano de quarzo algo duro y grueso. Despues de cernidos asi se han molido con ruedas de Molino en particulas mui finas, cuia sutileza se entenderá con decir que siendo aquellas de $3 \frac{1}{2}$ de diametro y dando como unas 114 bueltas cada minuto han molido 12 quintales cada una en el espacio de 24 horas. Cernida la arina con cedazos mui finos sobre que la escupen dichas ruedas y sacuden al mismo tiempo se han mezclado con dos tercios de arina que llaman de plata (silberschlich) tambien de Kremnitz á fin de hacer una mezcla que contuviese á poca diferencia 4 onzas de dicho metal por quintal, que es la riqueza con que se proponen beneficiar los Minerales los Autores de esta labor, y como no sea posible dar siempre á la citada mezcla quatro onzas justas, la presente salio á 4 onzas $2 \frac{1}{2}$ adarmes de plata, llevando cada marco de esta $2 \frac{1}{2}$ adarmes de oro. Mezcladas bien y exactamente las arinas, y añadidolas 10 libras de sal por quintal se quemaron de quatro en quatro en hornos de Kramer con dos lechos, ó suelos solamente, como se usan en esta manipulacion, teniendose por inutil el tercero, durando cada hornada de 5 hasta 6 horas y consiguientemente algo mas que lo regular que es de 4. Como aqui se formaron muchas pelotas ó globitos, asi por la humedad que suelen llevar los Minerales, como por las sales que se forman en los hornos durante la quema, fue menester cernirlos para separarlas, y molerlas despues y tostarlas en los mismos ornos, y con el mismo fuego por el espacio de dos horas, al cabo de las quales se sacaron y mezclaron con la demas arina que havia pasado por los cedazos. Ahora como por mui fina que sea la arina, que con ellos se cernio no dexe de formar algunas pelotillas que el azogue menos sutil que el fuego no puede penetrar para desprenderlas del metal que llevan, y asi mismo porque las arinas de plata que como dixe forman dos tercios de la mezcla sean algo groseras, pues no se molieron, sino con pisones en los Lavaderos para mayor seguridad, y contra lo que se practicó hasta alli se volvieron á moler, y á cernir.

Dispuesto y preparado asi el mineral se há amalgamado en quatro cubas diferentes, cuias dimensiones, como asi mismo el modo de hacerlas andar, y asegurarlas, ó aferrarlas puede verse en el adjunto dibujo. Hanse hechado en cada una 10 quintales y luego 21 libras de agua tibia por quintal, lo qual se practicó virtiendo la mitad caliente y la otra mitad fria, o inmediatamente $1 \frac{1 / 2}{\text { tt }}$ de cal que se aireó y apago con agua á fin de que destruyera, ó descompusiera con mas facilidad las caparrosas que se formaron en el horno, y que deshacen el azogue convertido en lis, quitandole su viveza natural, con que lo imposivilitan de abrazar la plata, y el oro, y finalmente por que parte del acido de la sal se habria volatilizado y perdido en el fuego, pues como diré fue algo largo, se añadio para resarcirlo. Hase observado por varios experimentos que el acido de la sal es indispensable para el beneficio del oro y de la plata por azogue anden ambos metales

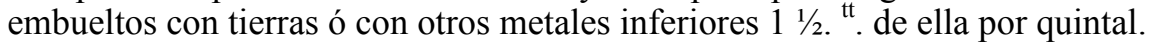

Hechados todos estos materiales y tapadas mui bien las cubas hanse hecho andar sobre su exe, dandolas de 33 hasta 36 bueltas cada minuto, cuia velocidad es necesa- 
ria para que dichos materiales se mezclen bien y exactamente unos con otros, y andada asi la Maquina como unas tres horas, y viendo que la pasta havia adquirido aquel grado de firmeza que por varios experimentos se sabe ser la mas adequada y propia para esta labor y en particular para la saca del oro lo qual se conoce quando apretando con un palo con mediana fuerza puede clavarse hasta el fondo de la cuba, ó bien quando, sacando un puñado de ella pueden formarse pelotas sin emporcar mucho la mano por demasiado blanda, ni dexarla mui limpia por demasiado seca y dura, dando digo estas señales al cabo de tres horas se han hechado quatro libras de cobre (hechose en tegitos de tres pulgadas de largo y una de ancho y $1 \% / 8$ de grueso, y veinte y cinco de azogue por quintal, el qual se tarda en poner hasta ahora á fin que la cal impregnada de aire fixo se una primero con el accido vitriolico de las sales metalicas, forme el yeso indisoluble en el agua, y no lo ataque tan facilmente. El cobre se hecha juntamente con el por que se emplea con el fin de que teniendo la propiedad de atraher el amalgama, y el azogue que andan nadando por la cuba aumente la Masa y peso de ambos agarrando, ó abrazando muchas particulas á la vez con que engruesan, y cobran bastante cuerpo para caer é incorporarse con la pella, ó bien con el fin, y me parece el mas fundado de que uniendose con los acidos del vitriolo de Plata, ó de la Plata cornua caiga en forma metalica, ó bien si mas se quiere para hacer caer el azogue que en todo caso huviese servido para destruir ambas sales con lo qual se remedia á mucha parte de su consumo.

Hechados el cobre y el azogue se han tapado las cubas exacta y casi hermeticamente ciñendo los tapones con un poco de futiro, o de cañamo, y poniendo entre ellos y el orificio una capa de barro que no quedara endedura ninguna por donde pudiera escaparse el último metal. Hanse buelto á hacer andar luego algo mas templadamente que primero, y de modo que dieran como unas 26 bueltas cada minuto, por que dandolas mas se ha observado que el azogue se desmenuza y convierte demasiado en Lis. Boltearonse asi por el espacio de ocho horas, durante las quales se destaparon varias veces para examinar y asegurarse si la pasta se mantenia con la debida firmeza, ó espesor, lo qual se conoce ahora, quando sacando un poco de ella se halla toda sembrada, y llena de globitos de azogue á manera de rocío encima delas hojas, conservando el brillo, ó espesosidad, si asi puede decirse, que le es natural. Repitiose algunas veces el parar, y destapar las cubas por ser aquella circunstancia de la pasta esencialisima á la presente labor y reparé algunas veces que al hechar el agua mas bien se virtio una libra menos que una libra mas, pues en aquel caso se remedia, añadiendo la que la falta en vez que en el otro anda perdida la mayor parte del oro, y he oido varias veces decir á Mr. de Ruprecht que solo media libra mas de la que es menester causa una perdida notable de este metal.

Haviendo andado las cubas con la dicha velocidad por el espacio de ocho horas, cuio tiempo es necesario al azogue para abrazar el oro, y la plata que por la primera labor donde obran todas la sales por quien se halla impedida, puede recogerse se han hechado 7. "t de agua fría en cada una á fin que el azogue y amalgama que estan esparcidos por en medio de la pasta se fueran juntando al fondo, y también por si algu- 
na cantidad de ella no huviese podido penetrarla el azogue á causa de ser mui espesa se consiga de este modo. Repitiose esto quatro veces diferentes por el espacio de quatro horas, haciendo andar á cada una mas reposadamente las cubas, al cabo de las quales se llenaron hasta arriba, y taparon los orificios menores no con tapones enteros como hasta aqui, sino con otros agugereados por en medio, donde se introduce una clavijuela de madera para poder governar mejor y contener mas facilmente el azogue, y amalgama quando huvieren de sacarse. Hanse hecho andar despues de esto lo mas reposadamente que se ha podido, dando no mas de quatro, ó cinco bueltas cada minuto, y parandolas de alli a media hora se sacó el amalgama, tirando la clavijuela, y poniendo primero un vaso de fierro algo hondo debaxo para recibirla. Bolvieronse á tapar luego en saliendo algo turbia, á hacerlas andar con el mismo reposo, y á abrir de alli á un quarto de hora para sacar lo que se huviese juntado en el fondo, lo qual se executó hasta 3, ó quatro veces según se vio que salia mas, ó menos y he notado en varias ocasiones que á la tercera han chorreado hasta treinta libras de azogue y amalgama. No dando mas de este modo se llenó de agua todo lo que se sacó de uno y de otro y haviendo andado un tanto reposadamente se probo otra vez si salía mas, y no saliendo se taparon con el tapon entero y arrimando con un palo por el orificio mayor las planchitas de cobre á un lado para que no impidieran cerrando el menor las lamas de salir, retirando el vaso en que se recogio el amalgama y afloxando el tapon de sacaron los residuos y conduxeron por canales á la Maquina de labar.

Como las lamas sean mui turbias y espesas al salir de las cubas, y hayan menester mas agua para que la Lis, asi de azogue, como de amalgama que quedó en las cubas caiga y se detenga en el suelo de la canal de trecho en trecho con barro hasta media altura por que estancandose alli en algun modo el agua, soltarán la lis mas facilmente, lo qual se ayudó todavia, poniendo á lo largo de la misma canal algunos rimeros de planchitas de cobre plateados de los beneficios anteriores, y que por la virtud que dixe mas ariba tenian, recogen algun tanto al pasar las lamas por entre ellas Particularmente andando uno, ó dos amalgamadores con unos rastrillos arriba y abaxo revolviendolas, con lo qual se rozan y tocan las particulas de azogue, y amalgama mas veces, cobran mas cuerpo, y caen al suelo. Observando exactamente estas circunstancias quedó en los residuos mui poco de uno y de otro de suerte que en la Maquina de labar se recogieron todos aquellos dias solo algunas onzas. Haviendose vaciado de este modo las cubas mas de la mitad se virtieron algunos cantaros de agua en ellas, y se sacó lo demás por el orificio mayor colocando en el una plancha de cobre llena de agugeros á fin de que las planchitas de este metal que todavia se hallaban dentro no cayeran en la canal, y se obtuviera asi todo separado.

Mientras que los residuos fueron saliendo de las cubas se tomó con una cazuelilla un poco de quando en quando hechandole inmediatamente en un plato alli junto donde añadiendole agua clara se despojó de la lis y azogue que llevava y con lo que se asentó despues en el suelo del plato se hizo la prueva ordinaria para saber la plata, que en dichos residuos quedaba. Las lamas de la Maquina de lavar la qual ando reposadamente todo el tiempo del vaciar de las cubas se sacaron sucesivamente por las 
llaves que se hallan á diferentes alturas de ella, probando primero con un Dornajo de madera algo largo y ahondado, si contenian todavia lis. Lo que quedó en el suelo que fue todos los dias como cosa de un palmo se sacó y lavó con las manos y agua fria.

El amalgama y azogue sacado asi de las cubas, canales y Maquinas de lavar se pesó todos los dias con el fin de saber quando se hiciese por copela el ensaye de las pellas quanto se havia consumido del ultimo aquel dia y precaver su perdida caso que fuese mucha. Luego de pesado uno y otro se hecharon en un saco de sarga mojado para que fuera mas tupido, y aforrado de lo mismo con el fin de separar el azogue superabundante, el qual cae facilmente por entre dichos lienzos, apretandolos blandamente. El amalgama, que quedó se puso en un vaso donde se bañó con un poco de azogue, para que avivandose fluiera, y pudiera lavarse con una esponja, lo qual se hizo hechandola agua y removiendola con un palo de madera hasta que saliera clara. Acabada de lavar se la sacó del mismo modo que primero el azogue que sela había hechado, y se puso luego en un plano inclinado y cerrado por los lados con listones (Fig.) á fin de que el azogue no se fuera por ellos quando se sacudiese. Estendiose aquí dandola dos pulgadas de alto y con golpes de maceta se apretó hasta que no se vio fluir mas azogue, y que el amalgama se havia adelgazado una buena pulgada con que parecio bastante firme y solida para desazogarla, siendo la plata al azogue como uno es á $6 \frac{1}{2}$ á poca diferencia. Luego con un molde (Fig. 8) de dos pulgadas de diametro se cortaron en panes cilindricos con que quedaron dispuestos para colocarlos en la desazogadera. Tambien he visto exprimir el amalgama despues de lavada y limpia con cubos de madera partidos á lo largo en dos partes iguales las quales se afirman con cercos de fierro que se dexan adredes algo floxos para que quando se apriete el amalgama, mediante una prensa (Fig. 8) y un cilindro de madera que se introduce en lo interior del cubo, pueda escaparse el azogue por entre las junturas. Despues de apretado y exprimido así, se sacó y cortó en cilindros de una pulgada de alto. Pero este ultimo modo me parece mas largo, y enfadoso que el primero el qual se usa ahora, por que se há observado que exprimiendo el amalgama con las manos, y por cueros los Amalgamadores particularmente en verano caen malos, pues se les hinchan las encias y babean, ó bien se les irritan las fibras y cobran temblores bastante fuertes.

De cada panecillo de amalgama preparado, asi, se tomó un poquito, y del que se juntó se pesaron todos los dias $1500^{\text {tt }}$ con las pesas de los Ensayadores, pusieronse con una copela cubierta con otra debaxo de mufta para disipar el azogue, refinose luego con plomo el boton de plata, y ensayó con agua fuerte para saber lo que se habia obtenido aquel dia de oro, y de plata.

Acabados de beneficiar los 293 quintales se juntó toda la plata y oro que se obtuvo durante ocho dias que se emplearon para la primera labor no haviendo podido andar siempre las 4 cubas, y se hallaron 138 marcos 1 onza, seis adarmes del primero y 1 marco, 7 onzas $11 \frac{3}{8}$ adarmes del segundo, que rebaxado uno y otro de 149 m. ${ }^{\mathrm{s}} 2$ onzas de plata, y de $2 \mathrm{~m}^{\mathrm{s}} 7$ onzas $12 \frac{1 / 2}{2}$ adarmes de oro cantidad que contenian los minerales, quedaron toda via en los residuos 11 marcos 10 adarmes del un metal, y 1 marco 11 adarme del otro, una cantidad se propusieron de sacar amalgamandolos 2 
vez y para asegurarse de qual modo saldria mejor la labor se hicieron 4 experimentos en las 4 cubas diferentes, llenado la una con residuos que se sacaron en la parte superior de los hornos de reververo, la otra con residuos quemados con $1 \frac{1 / 2}{\text { tt }}$ de sal por quintal, la tercera con otros quemados sin ella, y la quarta con los mismos asi como se sacaron del Lavadero, donde se havian depuesto y asentado. Acompañaronse todos con las mismas circunstancias, asi por lo que toca al movimiento como á los materiales que se les hecharon, y dieron los siguientes resultados.

El primero dio 6 onzas de amalgama, cien partes de la qual rindieron $15 \frac{1}{2}$ de plata fina: cada marco de esta $5 \frac{2}{8}$ adarmes de oro, y los residuos quatro de plata por quintal.

El segundo dio $1 .^{\text {tt }} 21 / 2$ onzas de amalgama, cien partes de la qual rindieron quince de plata fina; cada marco de esta $4 \frac{1}{2} 2$ adarmes de oro, y los residuos solo uno por quintal.

El tercero dio $1 .^{\mathrm{tt}}$ de amalgama cien partes de la qual rindieron 14 de plata fina; cada marco de esta $6 \frac{1}{2}$ adarmes de oro, y los residuos 4 de plata por quintal.

El quarto dio $51 / 2$ onzas de amalgama, cien partes de la qual contuvieron catorce y media de plata fina, cada marco de esta $4 \frac{3}{4}$ adarmes de oro, y los residuos $4 \frac{1}{2}$ de plata por quintal.

Por donde se vé que quemando los residuos con $1 \frac{1 / 2}{}{ }^{t t}$ de sal por quintal se saca mas oro y plata que de los otros tres modos, y aunque es verdad que el prepararlos asi ocasiona algunos gastos sin embargo el oro y la plata que se saca de mas los resarcen mui bien, y asi se determinó tostarlos con la dicha cantidad de sal por el espacio de 4 horas en los mismos hornos de reverbero, que primero, y con el mismo fuego, no dexando jamas apagar la llama, como suele hacerse con los Minerales que contienen mucho azufre, sino añadiendo leña así como se iba gastando hasta que el cabo de dicho tiempo se sacaron y amalgamaron en las mismas cubas procediendo del mismo modo que se executó la $1^{\text {a }}$ labor, aunque sin hecharles mas cal ni mas sal. Su beneficio duró por el espacio de ocho dias, sacando siete marcos diez adarmes de plata y 4 onzas $9 \frac{1}{1} 2$ adarmes de oro que juntado con la cantidad de ambos metales que se sacó mediante el primer azogue hacen 145 marcos, 2 onzas del primero, y 2 marcos 4 onzas $4 \frac{1}{8}$ adarme de oro. $\mathrm{Y}$ asi quedan en los desechos 4 marcos 4 onzas de plata $\mathrm{y}$ 3 onzas $8 \frac{3}{8}$ adarmes de oro.

Por la primera labor de consumieron $49 .{ }^{\text {tt }} 5 \frac{1 / 2}{2}$ de azogue y $40 .{ }^{\text {tt }} 2 \frac{1 / 2}{2}$ onzas de cobre, y por la segunda no solo no se perdio nada del primer metal, antes bien se lograron $10{ }^{\text {tt }} 6$ onzas del que havia quedado en forma de Lis en los residuos. De cobre se consumieron $15 .^{\text {tt }} 61 / 2$ onzas que juntado uno y otro se hallará haverse consumido á poca diferencia 4 onzas de azogue, y 6 de cobre por marco de plata.

Es por demas explicar de pronto las utilidades, y ventajas de esta manipulación sobre la de los calderos y cocimiento, y sobre la de la Maquina, ó torno de que hé hablado al principio de esta descripción, pues las advertirá al instante cualquier inteligente en estas materias, leyendola, y asi solo apuntaré las dos mas importantes. La $1 .^{\mathrm{a}}$, es que amalgamando por este metodo minerales con 4 onzas de plata, contenien- 
do esta $2 \frac{1}{2}$ adarmes de oro por marco solo se pierden 3 por $\%$ del primero y 15 por $\%$ del segundo como puede verse por la cuenta del que se ha sacado y quedado en los residuos, en vez que según el metodo de Born, beneficiando minerales de la misma especie y riqueza se han perdido mas de 8 por $\%$ de plata y pasados 60 de oro, como consta por los documentos y cuentas de los Minerales que se han entregado á esta labor y del oro y plata que se ha buelto á sus Dueños ó a la casa de Moneda desde principios del año 1786 hasta hoi: La segunda ventaja es que se ahorran los gastos continuos de los calderos y molinetes que han formado hasta aqui mas de un tercio de los de toda la Fabrica, por que una cuba dura por lo menos quatro meses que contados á veinte y cinco dias de trabajo pueden amalgamarse 1000 quintales en cada una, y como no cueste mas de 8 flor. sale cada quintal, amalgamandolo dos veces á un Keutzer no mas en lugar que con los calderos sale por lo menos á $12 \mathrm{Kr}$. solo la primera labor, y consiguientemente á $24 \mathrm{Kr}$. la labor entera, y asi en un asiento regular donde se amalgamaren 36000 quintales se ahorran 13600 flor., y en el solo cerro del Potosi donde se benefician al año según trahe Acosta 300 mil quintales quanto no se ahorra? Y quanto no se huviera despediciado siguiendo el metodo de Born? Durante los meses de Septiembre, Octubre, Noviembre y Diciembre del año pasado se amalgamaron en el Asiento de Neusohl 900 marcos de Plata y los gastos de la Fabrica subieron aquel tercio a 13600 flor. llevandose mas de la mitad las hechuras, y remiendos de los calderos y Molinetes, cosa que pone espanto, y que havia de sobrepujar todas las ventajas sobre la fundicion, aunque realmente huviese havido algunas. No puede entenderse como no se cayo en ello desde el principio, lo qual prueva evidentemente quan juiciosos, y desapasionados hayan de ser los sugetos de quien se hechare de quien se hechare mano para que examinen un descubrimiento qualquiera, é informen de el al Ministerio especialmente en un ramo tan importante en nuestros Reynos como el de Minas y tan desconocido y tan general, pues hay que atenerse casi sin replica ninguna á lo que dichos sugetos informasen; una cuba aserrada y del tamaño que muestra el dibujo cuesta de 70, á 75 flor. pero nada de ella se pierde, sino es las duelas, sirviendo aros, exes y todas las demas herramientas para la nueva, como lo he visto executar varias veces.

\section{Advertencias que pueden servir a un Beneficiador}

Consta por una infinidad de experimentos que el oro no puede sacarse por azogue, sino es quando la pasta es algo firme y espesa aunque la plata al contrario quando es mui clara y sobreaguada, como lo prueba la mucha que se há sacado por peroles y cocimiento, cuia circunstancia no puede causarla por cierto la poca afinidad, ó tendencia del azogue al oro pues se sabe que es mucho mayor que la de la plata, y asi el quedar aquel en los residuos quando esta está, yá amalgamada y abrazada por el azogue, no puede atribuirse sino es á alguna causa física, y mecánica, y en ninguna modo á alguna chimica, y en particular me parece á su mayor densidad, pues no puede dudarse, que el azogue se une con los cuerpos con quien se amalgama poco á poco 
sucesivamente, y como carcomiendolos, y segun esto claro está que una particula de oro necesitará mayor tiempo para unirse con el, que una de plata, plomo, ó cobre: á cuio inconveniente no veo pueda precaverse sino es haciendo la pasta algo firme por que de este modo no solo obra el azogue que boltea encontrandose, y pegando con varias particulas de dicho oro como sucede beneficiando por peroles y Molinetes, sino tambien y aun mucho mas el que detenido y mezclado en lo interior de la pasta tiene sobrado tiempo para agarrar, ó disolver, si asi puede decirse las que huviere junto á el pudiendo verificarse aquel Proverbio de los Químicos: La disolucion ama el reposo. Hallanse bien nuestros Amalgamadores con dexar sus caxones despues de rebueltos 8 , ó 10 dias sin tocarlos aunque tal vez ignoran la causa. Asi mismo por que al encontrarse una particula de oro con otra de azogue, aquella, ó esta no pueden ceder tan facilmente, como quando la pasta es mui clara por ser el rozamiento y la presion mucho mayor, y asi se efectúa mas pronto dicha union pues es cosa sabida entre Chimicos que el peso de un disolvente contribuye mecanicamente á deshacer un cuerpo qualquiera, y finalmente por que aquí no hay el inconveniente que forzosamente há de experimentarse quando la pasta es mui clara, y es que moviendose esta y el oro rapidamente muchas veces seria mayor el movimiento mecanico que se le daba que el de su afinidad con el azogue. Otra razon mas poderosa á mi parecer por que se extrahe tan poco oro, y con tanta dificultad es por que tampoco llevan mucho los Minerales y es cosa sabida por quanto mas pobres son en un metal, tanto mas queda en los residuos á proporcion del que se saca, y asi amalgamando minerales de diversas riquezas, aunque de la misma calidad se saca mas de los mas ricos á proporcion del que queda en los residuos que de los mas pobres: por exemplo si en una cuba se amalgaman diez quintales de mineral con quatro onzas de plata cada uno y en otra tambien 10 de la misma calidad con solo dos onzas, los residuos quedarán en una y otra parte con quatro adarmes de plata como lo enseña la experiencia. Ahora si el metal que se saca havia de ser en proporcion directa del que queda en los residuos, la siguiente fuera verdadera: $37 \frac{1}{2}$ onzas de plata sacada de los 10 quintales mas ricos son á $21 / 2$ onzas que han quedado en sus residuos, como $171 / 2$ onzas sacadas de los Minerales pobres son á $2 \frac{1}{2}$ que quedaron en sus correspondientes residuos lo qual es falso, y tanto mas falso quanto mayor distancia de riqueza huviere entre los minerales que se beneficiaren, pues labrando residuos de quatro adarmes de plata á penas se saca algo, quando de dos menos, y quando de uno nada, lo qual prueva que esta labor sigue mas bien la proporcion inversa que la directa. Por donde se entenderá por que se logra y logrará siempre poco oro respectivamente á lo que se saque de plata conteniendo los minerales onzas de ella, y no mas de un adarme de oro; quiero decir porque el tanto por $\%$ del primer metal será siempre mucho mayor, que el que se perdiere del segundo, y asi mismo quan engañados andan los que atribuyendolo á afinidades y raciocinios chimicos sin saber, ó consultar en algun modo la Fisica y Mecanica hacen experimentos y mas experimentos, tentativas, y mas tentativas. La razon de esto la expuse al ultimo de la descripcion del Ensaie por copela de los residuos del amalgama de que hé hablado al principio de esta. 
Aunque la firmeza de la pasta sea tan esencial al amalgama por cubas, sin embargo no debe serlo sino hasta un cierto termino pasado del qual sucede lo propio que quando la pasta es mui clara, pues en aquel caso todo el azogue anda junto sin repartirse por entre ella por que formando varias endeduras dá lugar á que el azogue escape al instante al fondo; y asi es menester guardar un cierto termino de modo que dicha pasta adquiera con una cantidad determinada de agua una especie de pegajosidad, ó consistencia con que pueda mas que con su solided y firmeza contener el azogue.

Para los Minerales, cuio beneficio hé descrito han vastado $21 .^{\text {tt }}$ de agua por quintal; pero para de otra especie, ó calidad no será menester tanta, ó bien mas conforme fueren mas, ó menos pesados, según se les hechare mas, ó menos sal al quemarlos, se expusieran mas, ó menos al aire, ó fueren sutilmente molidos, de suerte que un quintal de esudio que llaman aquí sohe-speise, un compuesto de fierro, arsenico, antimonio, cobre y plata que se obtiene fundiendo minerales de plata gris, y de cobre antimonial, quando la mezcla contiene poco azufre; ó bien de cobre negro con 14 , ó 15 . ${ }^{\text {tt }}$ há tenido vast. ${ }^{\text {te }}$ para sacarle el Oro y la Plata; uno de mineral mezclado con dos tercios de arinas de los Lavaderos despues de quemado há necesitado de 21 , hasta 23 . ${ }^{\text {tt }} \mathrm{y}$ otro de mineral sin mezcla de dichas arinas, no necesita tanta sin duda, por que no está despojado de la arcilla que es mas grasa y untuosa que las demas tierras y de que carecen las harinas de los Lavaderos por haversela llevado el agua con que se lavaron: tampoco se necesita tanta si se queman con mucha sal, y exponen despues al ayre, pues el acido de esta forma casi con todas las tierras, y metales, sales deliquescentes, ó que atrahen la humedad de la atmosphera. Estas, y otras razones impiden el que pueda darse una regla general sobre la cantidad de agua que se les huviere de hechar, pues no puede ser ni en razon inversa de su pesadez especifica y en razon directa de los volumenes; y en verdad que aunque pudiera guardarse esta proporcion no fuera posible en un Asiento donde se beneficia una cantidad crecida de ellos, servirse de un medio tan delicado, y enfadoso, y mayormente, pudiendo como hé dicho media libra de agua mas, ó menos por quintal hechar á perder el beneficio del Oro. Asi que me parece que todo Director de un Asiento debe antes de amalgamar una cantidad de mineral hacer algunos ensayes en pequeño, y en una cuba donde quepan como dos quintales (bien asi como Kramer aconsexa poner un horno de menor tamaño en todas las fundiciones) á fin de determinar la cantidad de agua con que se saca mejor el Oro que llevan, y despues de haverlo hallado pudiera con un palo, en cuia parte superior huviese un peso afixado probar hasta donde penetra, ó cala, y marcar aquel lugar del palo, ó vara por el mas propio para la labor de aquel mineral, y tambien pudieran señalarse en el todos los grados de firmeza que adquiere la pasta durante el beneficio, por que al principio es mucho mas solida, que de alli á dos ó tres horas que há andado la cuba y que los materiales se han bien mezclado, y azotado unos con otros, y asi en semejantes casos no se engañe nadie con pensar que no tiene bastante agua, pues se desengañará destapando la cuba de alli á dos horas.

Es menester llevar mucho cuidado al llenar estos vasos en no hechar el agua demasiado caliente, porque aunque es verdad que el Oro y la Plata se amalgaman con 
mas brevedad andandolo la pasta se ha observado que el azogue se divide, ó desmenuza demasiado, y asi todo lo que se gana en tiempo se pierde en este metal. Quanto mas firme y pesada es la pasta tanto mas se recalienta con el rozamiento continuo de unas partes con otras; y asi quando se beneficien Minerales cargados de metales inferiores (cobre negro por exemplo) hechese fria, ó bien menos caliente que quando llevasen solo tierras y pocos metales: lo propio sucede quando se quemaren con mucha cal que he visto hecharles quando corren riesgo de conglutinarse en los hornos. Hé observado algunas veces recalentarse tanto por alguna de estas circunstancias, y la de no tener entrada en la cuba el aire ambiente, que tomando un puñado con dificultad hé podido aguantarla en las manos.

Al llenar las cubas, no se ponga mas mineral del que es menester para que adquiriendo la pasta aquel grado de firmeza de que he hablado queden mas de un tercio vacias, por que es necesario que la mezcla, así como va bolteando al llegar al alto de ellas se precipite, y caiga sobre el azogue que se halla en el fondo, y mediante esta caída, ó impulso se mezclen todos los materiales que se han hechado con el azogue, lo qual no pudiera conseguirse si se llenaran hasta arriba, pues entonces formara la pasta una sola masa, bolteara sin sacudirse con el azogue y consiguientemente sin mezclarse y si se trabajara en vano. La experiencia há enseñado que en el lugar que ocupa un tunel de agua, de aquí que son como unas 99 libras de Paris, puede amalgamarse un quintal de mineral, y uno y medio de cobre negro. Una cuba donde caben 10 de dichos Toneles hasta el orificio esta llena con 10 quintales de mineral bien molido pero hechando el agua, y haciendola andar, dismiunuyese poco á poco hasta casi la mitad.

Según lo que se há dicho hasta aquí la presente manipulacion dura de 16 hasta 18 horas, necesitandose lo demas hasta 24 para vaciar y llenar con cuidado las cubas. Pareceme esto demasiado tiempo, y asi mismo que podria abreviarse hechando el azogue y el cobre dos horas despues de haber andado comenzando á aclarar la pasta quando huvieren bolteado por el espacio de 5, ó 6 lo qual se repitiera hasta quatro veces en dos horas, empleando las tres que quedan hasta 12 para llenar y vaciar dichas cubas; de cuio modo con la mitad de dicho tiempo se despachará. Es verdad que procediendo asi, los residuos quedarán tal vez ricos de media onza por quintal en vez de quatro adarmes; pero como hay que volverlos á amalgamar asi como asi, y sacandose los metales algo mejor quando las sales han yá desaparecido, esto no pudiera ser impedimento para que no se executara, y merece se hagan algunos experimentos sobre este punto, pues no importa menos que el ahorro de la mitad del tiempo y de los jornales. M. ${ }^{\mathrm{r}}$ de Ruprecht con quien lo he hablado los huviera seguramente hecho; pero el curso de Chimica de esta Academia le tiene al presente ocupado. Si los residuos del segundo beneficio, q. ${ }^{\mathrm{e}}$ seria tambien de 12 horas en vez de quedar con un adarme por quintal, quedaran con $1 \frac{1}{2}$ ó 2 ; examinese si lo que se pierde de plata, ó de oro si los llevaren los Minerales se ahorra en jornales con la mira de mantener siempre el logro de tiempo tan necesario, é importante en todo asiento algo abundante, y no lo es menos en los nuestros el ahorro de Amalgamadores segun la dificultad con que se provehen de los mas necesarios. 
Todo lo que se há dicho en esta Descripcion puede tambien entenderse del Beneficio de Minerales que contuvieren solo plata sin oro con sola la diferencia de que en este ultimo caso no será menester poner tanto cuidado en dar á la pasta y mantenerla con aquel grado de firmeza de que tantas veces hé hablado y explicado la causa. Schemnitz 24 de Abril de 1788 = Josef Ricarte. 